\title{
The Special Issue on Innovation in Health Science Education
}

\author{
Brad Wright $^{1} \cdot$ Lori Hornsby $^{1} \cdot$ Karen Marlowe $^{1} \cdot$ Dan Surry $^{1}$
}

Published online: 29 March 2018

(C) Association for Educational Communications \& Technology 2018

The topic of this Special Issue is Innovation in Health Science Education. As in virtually every other aspect of education, new technologies, advancing theories about how people learn, changing learner populations, evolving accreditation standards, powerful assessment and analysis tools, and emerging societal trends are having a profound impact on health science education.

We know that the nine papers in this special issue cannot possibly begin to adequately address the vast number of innovations currently being implemented in medicine, nursing, pharmacy, and related educational settings. But, taken as a whole, we believe the papers in this issue represent an interesting and impressive sample of the types of educational innovations going on today in health sciences education.

The first paper, by Wright, Hornsby, Marlowe, Fowlin, and Surry, describes our attempts to redesign a Doctor of Pharmacy curriculum using the backward design process. Our "Practice-Ready" pharmacy curriculum began with the development of a shared vision for the future role of the pharmacist, included the development of a set of ability-based outcomes, and used a team-based development approach to create truly integrated courses based on competencies and disease states.

In the second paper, Ryan and Beck provide an interesting example of how a team of educational specialists worked closely with faculty from multiple disciplines in the development of an integrated, competency-based Doctor of Pharmacy curriculum. Their paper includes discussions of key topics

\section{Dan Surry \\ dansurry@auburn.edu \\ Brad Wright \\ bmw0009@auburn.edu \\ Lori Hornsby \\ hornslb@auburn.edu \\ Karen Marlowe \\ marlokf@auburn.edu}

1 Auburn University Harrison School of Pharmacy, Auburn, AL, USA such as professional development, learning spaces, learner assessment, and successes and challenges, among others.

Ennis-Cole, Cullum, and Iwundu, authors of the third paper, address the important topic of physician leadership training programs. The authors describe a study in which they followed 10 physicians going through a six-month leadership development program. They present a series of findings that suggest such programs can be useful in helping physicians develop their leadership potential.

The fourth and fifth papers in this issue both focus on the topic of active-learning. Kelley and Liles, authors of the fourth paper, present an example of how active-learning and roleplaying can be used to help pharmacy students develop patient education skills. They emphasize that patient education is an important part of the Pharmacists Patient Care Process and that active-learning strategies can also be incorporated into interprofessional education activities. Eiland, author of the fifth paper, describes the perceptions of students in a redesigned course that made use of active-learning strategies. She concludes, among other things, that active-learning strategies can successfully be incorporated into a course where the instructor and students are at different sites and that activelearning strategies increased student confidence in their ability to complete course objectives.

Paper six, by Armstrong, Early, Burcin, Bolin, Holland, and No, describes two studies into how new communication tools can impact health science students' sense of community and connectedness while enrolled in online courses. Among their conclusions is that these tools may offer new ways to improve the retention of non-traditional health science students in an online environment.

In the seventh paper, Cleveland discusses digital portfolios and how they can be used to foster student reflection. $\mathrm{He}$ presents the findings of a study into the role of formative feedback on student reflection and concludes that practitioner-preparation programs should be encouraged to implement digital portfolios.

Ford, Sawyer, and Brown, authors of paper eight, describe the development of an interprofessional continuing medical 
education program with geriatrics-focused content. They point out the need for physicians in rural, underserved areas to engage in continuing medical education and conclude, among other things, that web-based modules are a potentially effective tool for the professional development of these physicians.

The final paper, by Hughes, Bradford, and Likens, presents a study of how short instructional sessions can be used to encourage faculty to incorporate technology into their courses. They explored faculty perceptions of technology's impact on communication, critical thinking, and collaboration. Their findings suggest "that faculty are using technology without a good understanding of the pedagogy related to instructional design." We are certain many readers of TechTrends will relate to that conclusion.

We hope these papers will encourage others in the health sciences to explore innovative teaching, learning, and assessment approaches and to submit research about their projects to TechTrends and other education-focused journals. We believe health science professionals have unique insights into educational innovation that can inform educational reform in other fields and that by engaging in a dialogue with the broader educational community, we can more effectively bring about positive change in the health sciences. Also, with the increased emphasis on interprofessional education in many healthrelated fields, there is a need to share our innovative practices outside of our traditional, more narrowly-focused, professional journals.

We would like to thank AECT, Springer, and Dr. Charles Hodges for allowing us the opportunity to publish this special issue and for giving us tremendous support and assistance throughout the process. We would also like to thank Paul Paratore of Auburn University for expertly reviewing and editing several articles in this issue.

If you have questions or comments about this issue or are interested in the topic of Innovation in Health Science Education, please contact us. We would enjoy hearing about your successes and challenges and possibly collaborating on future research and development projects. 